SHORT COMMUNICATION

\title{
Identification of fragrant gene, fgr, in traditional rice varieties of Sri Lanka
}

\author{
N.S. Kottearachchi*, E.G.D. Priyangani \& D.P.S.T.G. Attanayaka \\ Department of Biotechnology, Faculty of Agriculture and Plantation Management, Wayamba University of Sri Lanka, Makandura, Gonawila.
}

Revised: 21 July 2009 ; Accepted: 2011 October 2009

\begin{abstract}
A study was conducted to identify traditional rice varieties of Sri Lanka that possess the fragrant gene $(f g r)$ using designed allele specific markers based on the gene sequence of mutated version of Betaine Aldehyde Dehydrogenase 2 (BAD2), which is called fragrant gene. Fifty six rice accessions including several Basmati, Suwandal, Samba and Heenati varieties, were chosen for the polymerase chain reaction (PCR) amplification with $f g r$ would markers. Three fragments that would discriminate homozygous fragrant, homozygous non-fragrant and heterozygous individuals were amplified by multiplex PCR and the fragrance was evaluated phenotipically by potassium hydrooxide $(\mathrm{KOH})$ treatment. All positive accessions that amplified the $f g r$ allele expressed the fragrance with $\mathrm{KOH}$ treatment. Of the traditional varieties, one accession each from Suwandal and Samba and, two accessions from Heenati were identified as the $f g r$ genotypes that possessed mutated BAD2. Information from the investigation could be applied in breeding studies on aromatic rice suitable for the Sri Lankan environment, using marker assisted selection with local germplasms.
\end{abstract}

Keywords: Fragrant gene, marker assisted selection, Oryza sativa L., polymerase chain reaction.

\section{INTRODUCTION}

In Sri Lanka the rice breeding programmes of the past have laid much emphasis on increasing the yield potential without considering quality characteristics. Therefore, Sri Lanka imports high quality rice from other Asian countries, and in 2008, $5500 \mathrm{mt}$ of Basmati type rice was imported from Pakistan under the free trade agreement ${ }^{1}$. Importation of high valued Basmati type fragrant rice has been a requirement to support the tourist industry in the country. With the rapid improvement of people's living standards, fragrant rice is becoming more and more popular in the world rice market.
Among more than 100 volatile flavour compounds which contribute to rice aroma, 2-acetyl-1-pyrroline (2-ACP) has been identified as the primary cause for the distinctive fragrance in Basmati and Jasmine rice $^{2-4}$. The linkage mapping studies ${ }^{2-6}$ have previously determined that the gene responsible for fragrance $(f g r)$ or the causal factor for the elevated level of 2-ACP in rice, is located on chromosome 8. By comparison of the sequences of fragrant and non-fragrant genotypes it was found that an eight base pair deletion and three Single Nucleotide Polymorphisms (SNPs), in the betaine aldehyde dehydrogenase 2 (BAD2) enzyme, was the causal factor for the fragrance in Jasmine and Basmati rice $^{3}$. Non-fragrant rice varieties appear to possess a fully functional copy of the gene encoding BAD2 enzyme. As the fragrant varieties possess the $f g r$ or the mutated allele of BAD2, which is the cause for the loss of function in $\mathrm{BAD} 2$ enzyme, it is considered as a recessive gene. Loss of activity of BAD2 enzyme changes the direction of the biochemical pathway, which leads to the accumulation of 2-ACP. Rice along with many plant species possesses two BAD homologues, BAD1 and BAD2. The gene for BAD1 is located on chromosome 4 and it expresses a functional enzyme in both fragrant and non-fragrant rice varieties?.

Usually, the rice fragrance is determined by a number of sensory methods that have many limitations. Smelling of the leaves or grains after cooking is subjective and not always reliable as the ability to distinguish between fragrant and non-fragrant samples weakens with each successive analysis. Chemical methods involving smelling leaf tissue and grains after heating with water or reacting with $\mathrm{KOH}$ or $\mathrm{I}_{2}-\mathrm{KI}^{8}$ solutions are mostly practiced but they might cause damage to the nasal passages and 
senses become saturated after few analysis. Moreover all of these methods depend on personal variations. Identification of 2-ACP using gas chromatography is a reliable method, but expensive, time consuming and requires large samples of tissue which is not practical at early stages of the breeding programmes. Hence, identification of fragrance using molecular markers has advantages over traditional methods because they can be adopted to use in early seedling stages avoiding the effects of individual variations.

In Sri Lanka, only two high yielding aromatic rice varieties, namely Lanka Samurdi and At306 have been bred up to date. Unfortunately, aromatic rice cultivars, particularly Basmati rice from India and Pakistan often produce low yields because of low resistance to rice diseases and limited adaptation to a new environment ${ }^{6}$. Therefore, development of rice varieties suitable for the local environment with a fragrant trait is a current requirement. This can be easily achieved by introducing fgr gene of Basmati into local Sri Lankan rice varieties using MAS (Marker Assisted Selection). This study was conducted to discriminate fragrant and non-fragrant genotypes using $f g r$ specific markers, and to investigate local traditional varieties that possess $f g r$ to be used in breeding rice varieties suitable for local environments.

\section{METHODS AND MATERIALS}

Experimental site and planting material: This study was undertaken in the year 2008 at the Department of Biotechnology of the Faculty of Agriculture and Plantation Management, Wayamba University of Sri Lanka, Makandura, Gonawila. A total of 56 accessions (Table 1) was tested including Basmati, Suwandal, Samba, Heenati and other locally improved rice varieties. Seeds of all accessions were obtained from the Gene Bank of the Plant Genetic Resources Center (PGRC), Department of Agriculture, Gannoruwa, Peradeniya.

PCR Amplification: Leaves of two-week old rice seedlings planted on wetted petri dishes were used for the extraction of genomic DNA using a previously reported method ${ }^{9}$. A total volume of $15 \mu \mathrm{L}$ of PCR mixture consisting of $5 \mu \mathrm{L}$ of extracted DNA, $1.5 \mu \mathrm{L}$ of 10X PCR buffer, $1.2 \mu \mathrm{L}$ of $25 \mathrm{~m} \mathrm{M}$ deoxyribonucleotide triphosphates (dNTPs), $1 \mu \mathrm{L}$ $(20 \mathrm{pmol} / \mu \mathrm{g})$ of 4 types of primers (Hokkaido Systems Co Ltd., Japan) and $0.2 \mu \mathrm{L}$ of Taq DNA polymerase (Sigma, USA), were used for each amplification. The sequences $^{3}$ of the primers used were; External Sense Primer (ESP): TTGTTTGGAGCTTGCTGATG, Internal Fragrant Anti-sense Primer (IFAP): C ATA G GA G C A G C T GA A ATATATA C C, Internal Non-fragrant Sense Primer (INSP):
CTGGTAAAAAGATTATGGCTTCA and External Antisense Primer (EAP): AGTGCTTTACAAGTCCCGC. Amplification was performed in a T-Cy thermal cycler (CreaCon Technologies, The Netherlands) under the temperature profile consisting of an initial denaturing at $95^{\circ} \mathrm{C}$ for $5 \mathrm{~min}$ followed by 35 cycles of $1 \mathrm{~min}$ at $95^{\circ} \mathrm{C}$, $30 \mathrm{~s}$ at $58^{\circ} \mathrm{C}$ (primer annealing), $1 \mathrm{~min}$ at $72^{\circ} \mathrm{C}$ and final cycle of $5 \mathrm{~min}$ at $72^{\circ} \mathrm{C}$. Amplified PCR products $(5 \mu \mathrm{L})$ were electrophoresed in $1.3 \%$ agarose gel containing $0.5 \mu \mathrm{g} / \mathrm{mL}$ ethidium bromide. PCR amplification was repeated twice for the accessions that showed either the fragrant allele or fragrant phenotype, to confirm the particular data.

Fragrance evaluation: Three seeds from each accession were planted in $15 \times 30 \mathrm{~cm}$ sized black polythene bags under standard management practices in the net house. Fragrance was evaluated according to the slightly modified method described by Sun et al. ${ }^{10}$. When the plants were at tillering stage, $1 \mathrm{~g}$ of leaves was excised, cut into small pieces and incubated with $2.5 \mathrm{~mL}$ of $0.5 \%$ $\mathrm{KOH}$ in a petri dish at room temperature. After $15 \mathrm{~min}$ of incubation, samples were opened one by one and the odour was smelled by a three member panel. Evaluation was conducted batch wise, randomly, in order to avoid desensitization and evaluation of each sample was repeated twice. Smelled odour was categorized as fragrant if it was similar to the odour given by the positive control sample, Basmati-India (Acc.No. 11916).

\section{RESULTS}

In this study, external primers, ESP and EAP generated a fragment of approximately $580 \mathrm{bp}$ as a positive control in all 56 samples (Figure $1 \mathrm{~A}$ and B). Internal primers, INSP and IFAP have given two bands when paired with external primers, ESP and EAP. IFAP primer sequence has been designed specifically for the $f g r$ gene which gives fragrant genotype and INSP primer sequence has been designed specifically for the wild type sequence of $f g r$ locus which gives non-fragrant genotype ${ }^{3}$. Accordingly, as shown in the Figure 1-A and B, ESP and IFAP primer pair amplified a 257bp band showing the marker for fragrant genotype. Lanka Samurdi (Acc.No.8921) in Figure 1-A and Basmati-India (Acc. No.7018), Suwandal (Acc.No.4802) and Kaluheenati (Acc.No.3989) in Figure 1-B indicated the homozygous fragrant genotypes because they amplified $257 \mathrm{bp}$ band. EAP and INSP primer pair amplified a $355 \mathrm{bp}$ band showing a marker for non-fragrant genotype. Lane 1-3 of Figure 1-A and lane 8-9 and 11-12 of Figure 1-B revealed the homozygous non fragrant genotypes because of the presence of the 355bp amplified band. Lane 4 of Figure 1-A which contained Basmati (Acc.No.11127) indicated 
Table 1: Identification of the allele category based on the PCR amplification using fgr markers

\begin{tabular}{|c|c|c|c|c|c|c|c|}
\hline Acc.No. & Variety & $\begin{array}{c}\text { Genotype } \\
(+/-)^{*}\end{array}$ & $\begin{array}{c}\text { Phenotype } \\
(+/-) \#\end{array}$ & Acc.No. & Variety & $\begin{array}{c}\text { Genotype } \\
(+/-)^{*}\end{array}$ & $\begin{array}{c}\text { Phenotype } \\
(+/-) \#\end{array}$ \\
\hline Basmati & & & & 11041 & Kalu Heenati & - & - \\
\hline 07018 & Basmati Indian & + & + & 10728 & Kalu Heenati & + & + \\
\hline 11916 & Basmati Indian & + & + & 3851 & Kalu Heenati & - & - \\
\hline 06775 & Basmati Indian & - & - & 4086 & Kalu Heenati & - & - \\
\hline 07030 & Basmati Nepal & + & + & 4991 & Kalu Heenati & - & - \\
\hline 06944 & Basmati Pakistan & - & - & 5484 & Kalu Heenati & - & - \\
\hline 004920 & Basmati Sri Lankan & - & + & 3989 & Kalu Heenati & + & + \\
\hline 006152 & Basmati & + & + & 12095 & Kalu Heenati & - & - \\
\hline 11127 & Basmati & $+/-$ & - & 3264 & Heenati & - & - \\
\hline 11915 & Pusa Basmathi & + & + & 2087 & Heenati & - & + \\
\hline \multirow[t]{2}{*}{10984} & Subramanium Basmathi & - & + & 2098 & Heenati & - & - \\
\hline & & & & 6402 & Heenati & - & - \\
\hline \multicolumn{8}{|c|}{ Suwandal } \\
\hline 4366 & Suwandal & - & - & 4377 & Wanni heenati & - & - \\
\hline 5420 & Suwandal & - & - & Others & & & \\
\hline 4471 & Suwandal & - & - & 6316 & Hatapaduru vee & - & - \\
\hline 4197 & Suwandal & - & - & 6279 & Murungakayan & - & - \\
\hline 10729 & Suwandal & - & - & 6286 & Suli & - & - \\
\hline 4802 & Suwandal & + & + & 11599 & Oryza nivara & - & - \\
\hline \multirow[t]{2}{*}{10646} & Suwandal & - & + & 10637 & Jasmine & - & - \\
\hline & & & & 4655 & Rathal & - & - \\
\hline \multicolumn{8}{|l|}{ Samba } \\
\hline 3507 & Suwanda Samba & + & + & 4759 & Kurulu Thuda & - & + \\
\hline 2199 & Suwanda Samba & - & - & 4844 & Koththamalli & - & - \\
\hline 9629 & Suwanda Samba & - & - & 6278 & Mudukirial & - & - \\
\hline 4065 & Heen Samba & - & - & 4361 & Suduru & - & - \\
\hline 3910 & Heen Samba & - & - & 6376 & Dahanala & - & - \\
\hline 4239 & Heen Samba & - & - & Improved & & & \\
\hline 4692 & Seera Samba & - & - & 11030 & At306 & + & + \\
\hline \multirow[t]{2}{*}{3196} & Samba & - & - & 2762 & Bw265 & - & - \\
\hline & & & & 4483 & $\mathrm{Bg} 400-1$ & - & - \\
\hline \multicolumn{8}{|l|}{ Heenati } \\
\hline 4124 & Maha heenati & - & - & 8921 & Lanka Samurdi & + & + \\
\hline 11089 & Kalu heenati & - & - & 8920 & $\mathrm{Bg} 360$ & - & - \\
\hline
\end{tabular}

*(+) Presence of fragrant allele, (-) Absence of fragrant allele, (+/-) Heterozygous genotype

\# (+) Expression of fragrance by $\mathrm{KOH}$ treatment, (-) Absence of fragrance by $\mathrm{KOH}$ treatment

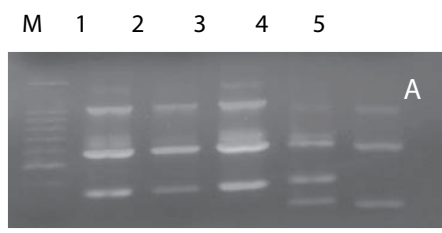

$\begin{array}{lllllll}6 & 7 & 8 & 9 & 10 & 11 & 12\end{array}$

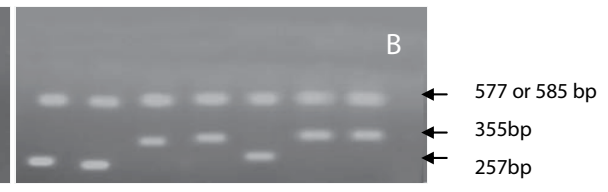

Figure 1: PCR profile generated from several rice varieties using fgr markers

A: Lane M:100 bp ladder DNA marker. Lane 1: Suwandel (Acc.No. 4802) Lane 2: Kalu Heenati (Acc. No.12095) Lane 3: Jasmine (Acc.No.10637), Lane 4: Basmati (Acc.No. 11127), Lane 5: Lanka Samurdi (Acc. No.8921)

B: Lane 6: Basmati-India (Acc.No.7018), Lane 7: Suwandal (Acc.No. 4802), Lane 8: Basmati-Pakistan (Acc.No.6944), Lane 9: Koththamalli (Acc.No.4844): Lane 10: Kaluheenati (Acc.No.3989), Lane 11: Rathal (Acc.No.4655), Lane 12: Kuruluthuda (Acc.No.4759) 
heterozygous genotype as this lane contained both $257 \mathrm{bp}$ and $355 \mathrm{bp}$ bands.

The odour type given by the smelling of chopped leaves with $0.5 \% \mathrm{KOH}$ was categorized as fragrant or non-fragrant as shown in Table 1. Of 10 types of Basmati tested, Subramanium Basmati and Basmati-Sri Lanka did not amplify the 257bp fragrant band although they expressed fragrance when smelling. Five Basmati accessions demonstrated homozygous fgr genotype, showing only $257 \mathrm{bp}$ allele and they also expressed aroma phenotypically with $\mathrm{KOH}$ treatment. Basmati type with Acc.No.11127 revealed that it is not a pure line for the fragrance as it expressed both $257 \mathrm{bp}$ and $355 \mathrm{bp}$ bands, the heterozygous allele combination. As expected this line did not produce any fragrance with $\mathrm{KOH}$ treatment because of the recessive trait. Other two Basmati accessions, Acc.No.06944 and Acc.No.06775 produced neither $f g r$ genotype nor fragrance phenotype even though they were labelled as Basmati.

One Suwandal accession, Acc.No.4802, one Samba accession, Acc.No.3507 and two Heenati accessions, Acc.No.10728 and Acc.No.3989 exhibited fgr genotype, and they did express fragrance phenotype with $\mathrm{KOH}$ treatment. One Suwandal accession, Acc.No.10646, one Heenati accession, Acc.No.2087 and Kurulu Thuda accession, Acc.No.4759, did not exhibit fgr gene although they were positive for the $\mathrm{KOH}$ treatment.

\section{DISCUSSION}

As multiplex PCR was conducted with four primers in a single PCR mixture, all polymorphic outcomes observable in one lane of agarose gel. This method gives an advantage by saving time and chemicals without compromising test utility for use by rice breeders in genotypic screening programmes for fragrance on a mass scale.

Of the tested improved varieties, only Lanka Samurdi and At306 exhibited 257bp fgr allele. Lanka Samurdi was developed in Sri Lanka, by crossing At402 variety and Basmati442 variety ${ }^{12}$. At306, a popular aromatic commercial variety in Sri Lanka, was developed by crossing At5 with IR49517-41-1-6-2-3. Development of a fragrant line takes nearly a decade as it needs much screening and field trials (Personal communication, B.D. Pathinayake). Therefore, the assessment system used in this study will be useful for the development of fragrant rice within a short time period.

There is no evidence to prove that the fragrance is a quantitative trait locus (QTL) because the fragrance assessed by gas chromatography does not exhibit normal distribution, Instead, the populations are distributed in a discrete manner ${ }^{4,7}$. Five traditional rice accessions expressed 2-ACP odour when compared with the positive controls, although it was not possible to prove the presence of the $f g r$ allele at BAD2 locus. The markers used in this study were developed based on the $8 \mathrm{bp}$ deletion located at the $7^{\text {th }}$ exon of BAD $2^{3}$. A previous study ${ }^{7}$ also reported that the $8 \mathrm{bp}$ deletion in fgr gene may not be the only cause for aroma and they suggested that at least one other mutation may drive the accumulation of 2-ACP. They found that several aromatic accessions containing 2-ACP, at the Genetic Resources Center of the International Rice Research Institute, collected from different countries, did not possess 8bp deletion in the BAD2. Accordingly, Sri Lanka has been mapped in the region having aromatic rice varieties lacking the $f g r$ gene. Proving this information, later, a study ${ }^{11}$ discovered another new fragrant allele causing the fragrant phenotype. The new fragrant allele has $7 \mathrm{bp}$ deletion in exon 2 of the same BAD2 homologue. It is not known whether the accessions that did not amplify the 257bp band in this study, but exhibited fragrance when smelling, contain null fgr allele in exon 2 or another mutated gene which increases the level of 2-ACP. Hence these accessions should be studied further to give some insight into the understanding of the aroma genes in Oryza sativa L.

In conclusion, all accessions that contained $8 \mathrm{bp}$ deletion at the $7^{\text {th }}$ exon of BAD2 or $f g r$ allele were positive for $\mathrm{KOH}$ treatment. Hence, breeders can be encouraged to utilize the discrimination procedure of fragrance and non-fragrance using ESP, IFAP, INSP and EAP markers. They can easily incorporate the $f g r$ gene when improving rice varieties by MAS by selecting the fragrant lines at early breeding cycles. One Suwandal accession, one Suwanda Samba accession and two Heenati accessions, possessing $f g r$ gene were identified among the Sri Lankan traditional rice varieties. Now breeders can utilize these accessions in their breeding programmes where Basmati varieties are difficult to be used. Moreover, these traditional varieties suitable for the native environment may have other beneficial characters that Basmati varieties do not possess.

\section{Acknowledgement}

The work was supported by the NRC Grant 09-11 by the National Research Council. The authors express their gratitude to the Gene Bank Division of the Plant Genetic Resource Center, Gannoruwa, Peradeniya for making available rice accessions. Authors thank Mr. B.D. Pathinayake at the Rice Research Station, Ambalantota and Prof. S.J.B.A. Jayasekara, Head of the Department 
of Horticulture and Landscape Gardening, Wayamba University of Sri Lanka, Makandura, Gonawila for providing necessary guidance and net house facilities respectively.

\section{References}

1. Anonymous (2008). Sri Lanka to import Basmati rice from Pakistan. http://oryza.com/Global-Rice/BasmatiRice/Basmati-Pakistan/srilanka-to-import-basmati-ricepakistan.html. Accessed on 31 of January 2009.

2. Bradbury L.M.T., Fitzgerald T.L., Henry R.J., Jin Q. \& Waters D.L.E. (2005). The gene for fragrance in rice. Plant Biotechnology Journal 3:363-370.

3. Bradbury L.M.T., Henry R.J., Jin Q., Reinke R.F. \& Waters D.L.E. (2005). A perfect marker for fragrance genotyping in rice. Molecular Breeding 16: 279-283.

4. Chen S., Wu J., Yang Y., Shi W. \& Xu M. (2006). The frg gene responsible for rice fragrance was restricted within $69 \mathrm{~kb}$. Plant Science 171:505-514.

5. Jain S., Jain R.K. \& McCouch S.R. (2004). Genetic analysis of Indian aromatic and quality rice (Oryza sativa L.) germplasm using panels of fluorescent-labeled microsatellite markers. Theoretical and Applied Genetics 109: 965-977.

6. Bourgis F., Guyot H., Gherbi E., Tailliez E., Amabile I., Slse J., Lorieux M., Delseny M. \& Ghesquiere A. (2008). Characterization of the major fragrance gene in aromatic japonica rice and analysis of its diversity in Asian cultivated rice. Theoretrical and Applied Genetics 117(3): 353-368.

7. Fitzgerald M.A., Hamilton R.N.S., Calingacion M.N., Verhoeven H.A. \& Butardo V.M. (2008). Is there a second fragrance gene in rice? Plant Biotechnology Journal 6: 416-423.

8. Sood B.C. \& Sidiq E.A. (1978). A rapid technique for scent determination in rice. Indian Journal of Genetics and Plant Breeding 38: 268-271.

9. Anushka K., Kottearachchi N.S. \& Attanayaka D.P.S.T.G. (2008). Identification of fragrance gene ( $f r g)$ in Sri Lankan rice varieties using Polymerase Chain Reaction based molecular markers. Proceedings of the 8th Agricultural Symposium, Wayamaba University of Sri Lanka. pp. 182187.

10. Sun S.X., Gao F.Y., Lu. X. J., Wu X.J., Wang X.D., Ren G.J. \& Luo H. (2008). Genetic analysis and gene fine mapping of aroma in rice (Oryza sativa L. Cyperales, Poaceae). Genetics and Molecular Biology 31: 532-538.

11. Shi W., Yang Y., Chen S. \& Xu M. (2008). Discovery of new fragrant allele and the development of functional marker for the breeding of fragrant rice varieties. Molecular Breeding 22: 185-192.

12. Department of Agriculture (2008). Rice Research and Development Institute, Sri Lanka. http://www.agridept.gov. lk.RRDI/Rrdindx.htm. Accessed by 10 June 2008. 